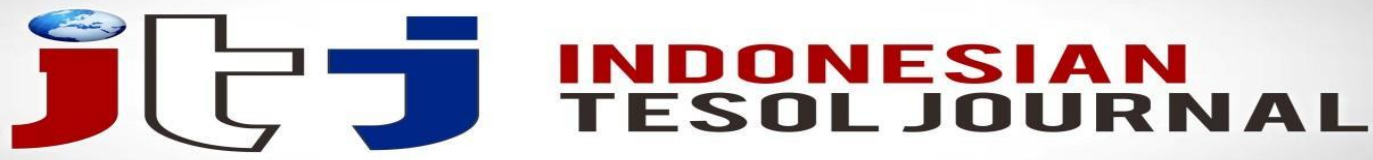

e-ISSN: 2622-5441(Online) Journal homepage: https://ejournal.iainpalopo.ac.id/index.php/ITJ/index

\title{
Stage Monologue and its Linguistic Features (Textual and Prosodic Analysis)
}

\author{
Elena Velikaya \\ National Research University, Higher School of Economics, Russia
}

Abstract: Spoken language production is considered to be one of the most difficult aspects of teaching a foreign language. It usually involves mastering pronunciation of sounds and intonation. If nowadays many teachers do not worry about the phonetic details of sounds, there is still focus on intonation as it has a great impact on the comprehensibility of the learner's English. This is a very important issue for future teachers because correctness of pronunciation is one of the goals of any spoken language programme, with students asked to produce quite extended spoken monologues and to follow the requirements of various intonational styles. The aim of this study is to analyse textual and prosodic characteristics of stage monologue - a text produced on a theatre stage or in a film. Analytical methods were applied in order to obtain information about textual features and prosodic stylistic markers such as pitch level, range, tone modifications, loudness, and tempo, and also to develop style-forming factors in stage monologue. Results show that the stage monologues analysed possess all necessary characteristics of a text: informational content, delimitation, continuum, coherence, cohesion and completeness. Further analysis of stage monologue showed that it can be characterised by such specific features as expressiveness, normativeness, effectiveness, and conversational character. Stage monologues also possess all necessary prosodic markers. Certain style-forming factors of stage monologue were also developed in this study, including delimitation, accentuation of key words, thematic centres and expressively prominent centres, type of composition scheme, and theme. These results will be of significant pedagogical value to students who intend to become English teachers, and to teachers involved in linguistics research.

Keywords: Artistic style; correct pronunciation and intonation; linguistic analysis; prosody; stage monologue; stylistic markers

\section{INTRODUCTION}

Russian authors who have studied stage monologue define it as a complete text, characterised - like any monologue - by continuum and cohesion, good text organisation, one-sided discourse, purposefulness and preliminary preparation (Yakubinsky, 1923). Krylova studied the written form of stage monologue and defines it as:

oral speech of one character which is semantically complete, has a clear composition, all elements of which are subordinate to the main idea; it is characterised by content which autonomously develops in a definite setting at a definite period of time (Krylova, 1979, p.59) (translation - author). 
In a play, it interacts with a dialogue or a polylogue but preserves its peculiar features. The production of such a monologue takes place in a theatrical environment which, in a way, is unreal, involving two kinds of participants: actors playing roles and silent spectators. All are aware of this artificiality because, due to the occasion and setting, spectators choose to "suspend ... disbelief" (Sanger, 2001, p. 6) and suppose that what they are watching is real. Stage monologues are 'primary' in reference to exposition, since they use the language of everyday speech, and 'secondary' by content, because situations which they describe form an abstraction, a summarised model. In the first case the description forms the communicative purpose, and in the second case the purpose is the creation of an abstract situation in which this model is realised. So, a specific feature of stage monologue is not solely the presence within it of picturesque or figurative means it deals not with one monologue but with two: one created while describing a communicative situation and the other created with the help of this situation describing another (abstract) one. It also possesses a certain number of expressive means which can be revealed through studying its language units, composition or structure.

Stage monologues used for teaching purposes represent artistic style and reading stage monologues from this perspective gives students an idea of what is artistic reading (in contrast to informational, academic, and conversational styles). On the one hand, it is a stylistic approach to teaching English; on the other hand, it is also essential for future linguists to approach stage monologue as a text and to understand how it is organised, what textual features it possesses and what are its prosodic characteristics. This understanding can help to build up specific pronunciation patterns in students' minds and help them to design their spokenword material correctly. So, the main objective of this study is to provide students with understanding of stage monologue's structure and composition, and its prosodic features. For the purpose of thorough linguistic analysis of such monologues, an extended textual analysis of stage monologues was carried out, as were auditory and acoustic analyses of a more limited number of stage monologues which represent typical examples of artistic style. Attention is first paid to monologues' textual features, then their prosodic features; finally, the importance of this study for teaching purposes is highlighted.

\section{MATERIAL AND METHODS OF RESEARCH}

The research in this article is based on the idea that the organisation of linguistic means is implemented in a text. It was carried out on stage monologues selected from two plays presented at British theatres: 'Look Back in Anger' by John Osborne, and 'The Birthday Party' by Harold Pinter, plus film adaptations of two Oscar Wilde plays, released on video: 'The Importance of Being Earnest' and 'An Ideal Husband'. The reasons for these choices are twofold: on the one hand, such modern writers as Osborne and Pinter are on the list of recommended authors in courses on British and American Literature; on the other hand, it is important to acquaint students with modern understanding and viewing of classical literature and authors such as Wilde. Modern film productions can attract students more than older theatrical productions. Monologues selected for research were grouped on the basis of two themes: 1) those with moral colouring, and 2) those characterising interpersonal relationships (approximately 100 monologues). Both auditory 
(perception) and acoustic analyses were employed to identify the prosodic characteristics of stage monologues. Auditory analysis was performed by several native speakers without special phonetic preparation, and Russian teachers of phonetics who have experience of this kind of analysis. Experts were to define: 1) the composition scheme of each of the monologues, 2) low, medium and high prominence of thematic centres and any other prominent parts of monologues, 3) tone characteristics of keywords, 4) pauses between intonation groups, phrases and dictemas identifying their character (syntactic, emphatic, with hesitation or without a stop in phonation), 5) intonation structure of thematic centres and other prominent centres and mark them graphically. With the use of auditory analysis the following information was obtained: the analysis of the setting, the composition of the monologue, the place of the thematic centre, pitch level, pitch range, type of the nuclear tone (Low (Medium) Fall, High Fall, Low Rise, High (Medium) Rise, RiseFall, Fall-Rise, Rise-Fall-Rise, Mid-Level), range of the nuclear tone (narrow, medium, wide), type of the head (Stepping head, Falling head, Sliding head, Rising head, Climbing head, Level head) (Sokolova et al., 1997, p. 164), loudness (low, medium, high), tempo (low, medium, high), and type of pause (very short, short, medium, long, very long, marked as $\xi,|| I,,|||| I||$, , respectively). Acoustic analysis was performed with the use of two computer programmes: Praat (v.4.0.53) and Speech Analyzer 3.0.1. Both of these programmes allow a researcher to obtain absolute, accurate measurements. The obtained absolute parameters were: measurements of fundamental frequency on a given chunk (unit) in $\mathrm{Hz}$ (for practical purposes fundamental frequency can be equated with pitch (Cruttenden, 1997, p.4)); absolute measurements of loudness on this chunk in $\mathrm{dB}$; absolute length (tempo) of the unit in seconds. The attained figures were relevant to male and female realisations. Since this research is based on the principle of relativity, it was decided to carry it out without reference to male, female, age, and social status data references, which enabled the researcher to trace trends for both genres. The parameters obtained included: pitch level figures (maximum, minimum, and average) in $\mathrm{Hz}$; pitch range figures as a difference between maximum and minimum figures in $\mathrm{Hz}$, which were then expressed as semitones (Blokhina \& Potapova, 1977); average loudness, which was counted as absolute loudness in dB divided by an averaged speaker indicator of loudness (the result was a relative number, for example, 1.6); the average length of a stressed syllable, which was counted as the sum of all measurements of the length of stressed syllables for each of the speakers individually, divided by the length of one syllable under investigation; the absolute average length of pauses in seconds as an average of the pauses in the utterance. The use of acoustic analysis made it possible to obtain objective data about the prosodic organisation of stage monologue, since this method, unlike those of auditory analysts, "involves precise and verifiable measurements" and is therefore "more scientifically respectable" even though "carried out on small amounts of data" (Cruttenden, 1997, p. 6). 


\section{RESULTS AND DISCUSSION}

\section{Stage monologue as a text, its textual analysis}

According to Galperin, who practised textual analysis, "text" is defined as a result of a text-creating process which is characterised by the following features: completeness, specific genre, presence of a title and several units (paragraphs) linked to one another through various types of connections - lexical, grammatical, logical, stylistic - with a communicative and pragmatic purpose (Galperin, 2006, p. 18) (translation - author).

It is important to mention that Galperin based this definition on written text, even though both written and spoken types of text are characterised by similar features. The first text feature is informational content of the text or "informativeness", which is realised through nomination of facts and events revealing text content and meaning. Galperin determines three kinds of information: factual, conceptual, and subtextual. The first kind - factual - contains facts, events and processes which take place in the surrounding world or in a hypothetical world. This kind of information is explicit by its nature, since it is expressed verbally, and all events are described with language means in their direct meaning. The second kind of information - conceptual - informs the reader or listener about the writer's point of view on facts, events and processes. So, the difference between these two kinds of information lies in the fact that the former gives more routine information, and the latter more aesthetic, literary information. The third kind of information subtextual - is always implicit and, due to the use of specific language means, generates associative and connotative meanings. Conceptual information is more typical in stage monologues, as the analysis shows, since it contains explicit markers - for example, metaphors, hyperbole, paraphrasing, comparisons and others. This kind of information reflects the relationship between events, understanding of cause-effect relationships, interpersonal relationships, and the complicated psychological and aesthetic cognitive connections between these elements. For example, in the play 'Look Back in Anger', Jimmy's monologue reveals the serious psychological condition in which he finds himself when he recollects his hardest grief, the death of his father. Conceptual information in this monologue reflects the value of family relations, attractions, and personal duty. For example:

Jimmy: For twelve months I watched my father dying - when I was 10 years old.

But, you see, I was the only one who cared. His family embarrassed by the whole business. ...

I spent hour upon hour in that tiny bedroom. All that was left of his life to one, lonely, bewildered little boy, who could barely understand half of what he said. All he could feel was the despair and the bitterness, the sweet, sickly smell of a dying man. ...।

You see, I learnt at an early age what it is to be angry - angry and helpless. And I can never forget it. ... 
Another main character, Helena, is on the edge of a morally motivated action: she decides to leave the man she loves because her love causes unhappiness to other people:

Helena: I shall never love anyone as I have loved you. But I can't take part - in all this suffering. I can't!

Another feature of stage monologue is delimitation. According to Galperin, delimitation of a text is the function of its composition, and the character of this delimitation depends on various factors; for example, the size of the parts of the text suitable for the perception of factual information, and the pragmatic purpose of the writer (Galperin, 2006, pp. 50-51). This research is based on M.Ya. Bloch's delimitation theory, the key point of which is dictema text structure. A dictema is a minimal thematic unit of text. It is characterised by such features as nomination, predication, stylisation, and theme (Bloch, 2000, pp. 56-67). It can consist of one or several sentences, even a paragraph; it can also form a text. In this research, a dictema is treated as the main text unit and the minimal thematic unit. It has its own content, structure, communicative organisation, and is semantically complete. The analysis of stage monologues in this research shows that each of the monologues contain from one to six dictemas. It is well recognised that the content structure of an utterance is composed of ideas, and the result of it is not a sum-total of ideas, but new ideas and meanings (Krylova, 1979, p. 12). The bearers of such new meanings are dictemas, which represent step-by-step increments of meaning which develop a monologue into a text. A good illustration of this is Lord Chiltern's monologue from 'An Ideal Husband':

Lord Chiltern: You've never been poor. You've never known what ambition is.

By now, Lord Radley was a cabinet minister. And as the Baron well knew, I was working as his personal secretary. One night, as usual, I was the last to leave the office. Later that evening, I wrote the Baron a letter containing highly confidential information ... and highly valuable information regarding the financing of the Suez Canal.

In a subsequent transaction the Baron made himself three quarters of a million pounds. I received from the Baron 110,000 pounds. I got exactly what I wanted. I entered straight into Parliament and I've never looked back.

Is it fair, Arthur, that some act of youthful folly should be brought up against me all these years later? Is it fair?

There are four dictemas in this monologue, each showing a quantitative accumulation of features. Moreover, they compel towards the thematic centre, which is the climax of the whole monologue:

Is it fair, Arthur, that some act of youthful folly should be brought up against me now all these years later? Is it fair? 
The main means used for delimitation in an oral stage monologue are phonetic means: pauses, tone movements, variations of loudness and tempo. Pauses can be of syntactic, emphatic, hesitational character, or without a stop in phonation. Dictemas are further subdivided into phrases and intonation groups ('intonation phrases' in Wells, 2007, p. 6). For instance:

a) syntactic pauses:

For twelve months I watched my father dying | when I was ten years old.||

This is not Alison's doing | - you must understand that.||

What any of it means, | I don't know.||

Follow the line, McCann, | and you can't go wrong.||

b) emphatic pauses:

You see, I learnt at an early age what it is to be ||| angry -|| angry and | helpless.|||

And I knew the word I had to remember $\|$ - respect!

c) pauses without a stop in phonation:

He'd come back from the war in Spain._You see,_and certain God-fearing gentlemen there had made such a mess of him, he didn't have long left to live.

I shall never love anyone as I have loved you. But I can't go on.

Honour thy father and thy mother._All along the line.

The next important text feature is continuum, which reveals through presentation of specific facts, opinions, and ideas within a definite thematic frame, and in accordance with a given composition scheme. Aristotle stated that "any whole has a beginning, a middle part and an end" (Aristotle, 1927, p. 49) (translation - author's). The first part of any written oral text serves as an introduction to the main theme of the text. The main part is the longest and most important because it presents the main content of the whole text. The conclusion and the introduction form a frame for the whole monologue. The conclusion also possesses an essential psychological meaning: the speaker summarises in it what was said in the main part. Stage monologue has a similar structure: an introduction is a reply to the context or its repetition, or provides preparation for the development of further ideas; then follows the development itself and, finally, a summary. The most important part of stage monologue is its thematic centre, which reflects the main idea of the monologue. According to the composition scheme of stage monologue, it can be placed either at the beginning or the end - in the final dictema - or in the middle of it. In each of these cases, the composition will follow a particular scheme: 1) idea - its development - summary; 2) cause - result conclusion; 3) frame kind (appears in the introduction and repeats in conclusion). For example, in Lord Chiltern's monologue from 'An Ideal Husband', the introduction is a reply to the context; in the main part, the central character describes the filthy deed he committed years ago; the conclusion is a summary which also has the psychological aim of appealing to the listeners to decide whether the effect of his deed is fair. In Goldberg's monologue from 'The Birthday Party', the frame composition scheme embraces the whole of the monologue: 
Goldberg: That's why I've reached my position, McCann, because I've always been as fit as a fiddle... .

Ha-ha! And that's why I've reached my position, McCann, because I've always been as fit as a fiddle.

Similar kinds of composition occur in other stage monologues.

The text feature of integration (coherence) is

combining of all parts of a text for the purpose of achieving its integrity. Integration can be realised by means of cohesion or can be based on associative or pre-suppositional relationships. ... If cohesion is realised syntagmatically, then integration can be treated paradigmatically, in other words, cohesion is linear and integration is vertical (Galperin, 2006, p. 125) (translation - author).

The analysis of stage monologues proves that each of the dictemas relates to the thematic centre through keywords (or thematic words), which can be identified in the thematic centre and are repeated throughout the whole monologue.

Much of the meaning ... is communicated by vocabulary or, to be more specific, by content words that function as keywords in an utterance. They tend to carry greater stress than function words, such as prepositions and articles, and auxiliary verbs (Richards, 2015, p.378).

These keywords serve as formal signs identifying the dependence of the meaning of various dictemas upon the thematic centre, and which help to decode the content of the monologue. Keywords can repeat in their original form or in various grammatical forms. For example, in the course of auditory analysis, in Jimmy's monologue from 'Look Back in Anger', the following keywords were detected: die, death, dying (which are grammatical variations on the word death) and the words bitterness and despair (which are close in meaning) and the thematic centre: I knew more about love, betrayal and death, when I was ten years old than you will probably ever know all your life.

Cohesion - another text feature of stage monologue - is a linguistic characteristic which reveals itself through syntagmatics of words, phrases, and dictemas. Cohesion is maintained by the development of the theme. The main grammar means which implement it are conjunctions, word order, anaphoric words, syntactical parallelism of constructions, forms of predicate, ellipses, and others. In the monologues analysed, the conjunctions and, as for, but, whether ... or, as ... as, the tenses Past Simple, Present Simple, Future-in-the-Past, syntactical parallelism of constructions (for example, I can't go on. I can't take part in all this suffering. I can't!), and anaphoric words were used:

Perhaps she pitied him. I suppose she was capable of that.

That's why I've reached my position, McCann. Because I've always been as fit as a fiddle.

Among lexico-grammatical means the following were identified: direct repetition of a word or a phrase, words formed from the same root (die, death, dying 
a dying man). Syntactical and stylistic means were represented by parallel constructions, repetition of the verb in imperative form and the use of the thirdperson pronoun in the meaning of the first person:

Jimmy: ... I spent hour upon hour in that tiny bedroom. All that was left of his life to one, lonely, bewildered little boy, who could barely understand half of what he said...

Completeness of the text as a text feature is a boundary to the development of content information. Such a text may not have a title, because its communicative purpose is achieved. All stage monologues selected for this analysis were proved complete. For example, the completeness of Goldberg's monologue is determined by its frame composition scheme when the main idea is repeated at the end of the monologue at full length. The completeness of Jimmy's monologue is also determined by its composition, but of a different type: 1) idea - its development summary. The summary in this monologue is also an allusion to the main character's recollections of his youth: I knew more about love, betrayal and death, when I was ten years old than you will probably know all your life. In some other monologues the completeness was demonstrated by a change in the theme, albeit connected with narration.

\section{Characteristic features of stage monologue}

The notion of style of pronunciation was introduced by M. Lomonosov in the eighteenth century (www.oplib.ru/...521185_the_phonetic_style_forming_means). There are different classifications of phonostyle. For example, L.V. Shcherba and R. Kingdon distinguish only two styles; Cruttenden uses oppositions of formal/informal, prepared/spontaneous styles (Cruttenden, 1997, p. 128); Jones speaks about five styles, and Gaiduchick also five, but based on different principles. Dubovsky (1978) builds his classification on the degree of formality of the situation (p. 82). Sokolova's classification is based on the purpose of communication, and on extralinguistic and social factors (Sokolova et al., 1991, p. 31). It distinguishes five phonetic styles - informational, academic, publicistic, artistic, and conversational - which are characterised by both segmental and suprasegmental features. Since this research deals mainly with intonation, it makes sense to call these styles 'intonational'.

Stage monologue refers to artistic style, so, according to Petrova (1981, p. 45), it is characterised by the following specific features: expressiveness, normativeness, effectiveness, and conversational character. "Expressive means initially materialistic speech - objective factors of inner life and individual qualities, the intentions and aims of an individual in his connections with reality" (Petrova, 1981, p. 45) (translation - author). Expressiveness is revealed through a definite choice of language means (in other words, stylisation) in accordance with the purpose of communication. For example, in Helena's monologue the phraseme can't and the key word suffering are accentuated more than the other words in this phrase, which is shown through an opposition of high and low pitch levels, medium and high rates of utterance. The phraseme can't in this phrase was more prominent due to the opposition of high and low pitch levels and low and high rates of 
utterance. Normativeness in oral speech manifests itself as distinct pronunciation, lack of reduction, and carelessness. Stage monologue is normative even though more democratic nowadays. For example, Gwendolen in the film 'The Importance of Being Earnest' sounds normative, and more natural playing the role of a young woman in love than would have the theatrical version of the 1950s. This is also due to a change of genre from satire to lyrical comedy.

Gwendolen: ... and my ideal has always been to love someone of the name of Ernest. There is something in that name that inspires absolute confidence. The moment Algy first mentioned to me that he had a friend called Ernest, I knew I was destined to love you.

Effectiveness of stage monologue is revealed through its pragmatics. From the phonetic point of view, the main language means of pragmatics are pitch level, pitch range, rate of utterance, loudness and the rate of nuclear tone change. A good illustration of the effectiveness of stage monologue is the example of blackmail in 'An Ideal Husband'.

Mrs. Cheveley: It was a swindle, Sir Robert. Let's call things by their proper names. It makes matters simpler.

Now I'm going to sell you that letter back, and the price I ask for it is your public support of the Argentine scheme.

You are standing on the edge of the precipice, Sir Robert. Suppose you refuse? Suppose I were to pay a visit to a newspaper office and give them this scandal and the proof of it? Think of their loathsome joy. Think of the delight they would have in tearing you down. Think of -

The prominence of the keywords back and support was implemented through the usage of High Rise on back and Low Fall on support, high loudness and very expressive pauses: long and very long between intonation groups.

Now||| I'm going to sell you that letter back, |||| and the price I ask for it is your public support | of the Argentine scheme.

Conversational character or, in other words, the "simple conversational speech" feature of stage speech, reveals, in its preciseness, clarity of an idea which is transmitted through logic, consistency, accurate word grouping and phrase buildup (Stanislavsky, 1954-1961, p. 108). This refers to the transmission of the main idea of the monologue, which is expressed in the thematic centre. For instance, in Goldberg's monologue it locates at the beginning of the monologue and repeats at the end, in keeping with the frame category of composition scheme.

Goldberg: ... That's why I've reached my position, McCann, because I've always been as fit as a fiddle.

... Never, never forget your family. ...

... And I knew the word I had to remember - Respect!

... Ha-ha! And that's why I've reached my position, McCann, because I've always been as fit as a fiddle. My motto: work hard and play hard. Not a day's illness. 
The prominence of the keywords position, motto, family, and respect is achieved by higher loudness and the speed of the nuclear tone change. The prominence of the whole of the thematic centre equals 12 semitones, which demonstrates the presence of the nuclear peak. Auditory analysis shows the prevalence of syntactic pauses, short intonation groups, Mid-Level heads, and High and Low Falls. The main character sounds confident and persuasive, as indicated by a wide range and high loudness. This combination of prosodic parameters reflects the willingness of Goldberg to get his message across in a simple way, and this appears very effective.

\section{Prosodic markers of stage monologue, its stylisation}

Despite the fact that intonation in stage monologue originates every time in speech production, as established by the producer and interpreted by the actors, it has its own laws. In the Russian theory of theatrical art, on the basis of main patterns, some stereotypical speech patterns were developed. Konstantin Stanislavsky looked into the laws of intonation and logic, accentuation rules, delimitation of phrases into intonation groups, intoning rules, described intonation patterns, and punctuation. While reporting on some punctuation means - dots, for example - he wrote: "the voice neither rises nor falls, it melts and goes away without completing the phrase ...", "a comma does not complete a phrase but sends it up as if to the next floor", "pitch level and speed of voice rise in the intonation of a question ... create different degrees and force of a question" (Stanislavsky, 19541961, pp. 326-328) (translation - author).

Basic intonation patterns are well researched in Russian theatrical school, and they are used in teaching stage speech; for example, the intonation of a statement, of a question or an exclamation, of an imperative sentence. All prosodic characteristics which help to form various intonation patterns depending on the type of speech and context have a stylistic character, and studying these characteristics helps in describing a particular style. This research shows that delimitation of a monologue into its constituent parts realised through pauses is one of the features which helps in identifying and forming a style. Stage monologue is a prepared oral text which is comprehended and interpreted by actors' syntactic pauses, separating one dictema from another, one phrase from another, and one intonation group from another, and one should prevail with it. For example, in Helena's monologue (first dictema):

Helena: Very well.|||| I'm going downstairs to pack my things. || If I hurry, I shall catch the 7.15 to London. |||| (two pauses are very long - 1.15 sec and $1.68 \mathrm{sec}$, one pause is long $-0.78 \mathrm{sec}$ ).

The end of the second dictema in this monologue is marked by a very long pause $(5.44 \mathrm{sec})$, as is the end of the monologue $(3.83 \mathrm{sec})$. At the same time, a very short pause $(0.12 \mathrm{sec})$ was identified at the end of the intonation group in the following example:

Helena: In fact, \she's just been trying to talk me out of it. 
Apart from syntactic pauses a few emphatic pauses were detected in this monologue:

Helena: But |||| I can't go on.|||| I can't take part in all this||| suffering.|||| I can't.|||| (four pauses are very long $-0.98 \mathrm{sec}, 1.3 \mathrm{sec}, 1.16 \mathrm{sec}, 5.38 \mathrm{sec}$ and one long pause $-0.87 \mathrm{sec}$ ).

The semantic meaning of pauses is determined by the aim of conversation on the one hand, and the objectives of the setting and tempo-rhythm relationship on the other. The combination of a very long syntactic pause and a Low Fall at the end of the phrase (entirely) makes the whole phrase sound categorical and resentful:

Helena: It's my own decision entirely.

A combination of a long emphatic pause and a High Fall on suffering adds sincerity and intensity to the feelings, creates an impression of complicity:

\section{Helena: I can't take part in all this||| suffering.||||}

Auditory analysis shows that Level heads prevail in this monologue, which usually characterises conversational style, but there are more Stepping, Sliding and Falling heads which are typical of artistic style. A vivid illustration of a combination of a very long emphatic pause and a Rise-Fall is given in Jimmy's monologue ('Look Back in Anger'):

Jimmy: ... angry and |||| helpless,

and also a combination of Low-Level head and a Low Fall with increased loudness:

Jimmy: And||| I can never forget it.

Another phonostylistic feature of stage monologue, according to this research, is accentuation of keywords (thematic words) which build up a thematic lathing of the monologue. For example, in Goldberg's monologue, the keywords are: opinion, true, life, respect, go wrong, and hard. The lexeme opinion was prominent due to the opposition of medium and narrow range, and the slowingdown of tempo of utterance, combined with a Low Fall. The word life was marked by widening the range and increasing the tempo of utterance, and it was pronounced with a Low Fall. The lexeme wrong stands out due to a narrowing of the range, a tempo slowing-down, and High Fall. The word true was prominent due to three prosodic parameters: widening the range, increasing the loudness and slowing down the tempo, accompanied by a High Fall. The lexeme respect prosodically had a narrower range, a higher loudness, and a Mid Fall. The word hard in the fifth dictema was also prominent due to narrower range and slower tempo. The results of this acoustic analysis are given in Table 1 .

Table 1. Prosodic prominence of keywords in stage monologue (second thematic group)

\begin{tabular}{|c|c|c|c|c|c|c|}
\hline \multirow{2}{*}{ Lexeme } & \multicolumn{2}{|c|}{$\begin{array}{c}\text { Pitch range } \\
\text { (in semitones) }\end{array}$} & \multicolumn{2}{c|}{$\begin{array}{c}\text { Loudness (relative } \\
\text { parameter) }\end{array}$} & \multicolumn{2}{c|}{$\begin{array}{c}\text { Length (tempo) } \\
\text { (in syllable/sec) }\end{array}$} \\
\cline { 2 - 7 } & Nucleus & Background & Nucleus & Background & Nucleus & Background \\
\hline opinion & 9 & 3 & 1.7 & 1.6 & 2.2 & 8 \\
\hline true & 20 & 5 & 1.7 & 1.5 & 2.1 & 4.3 \\
\hline life & 15 & 6 & 1.8 & 1.7 & 1.72 & 4.2 \\
\hline
\end{tabular}




\begin{tabular}{|c|c|c|c|c|c|c|}
\hline respect & 1 & 5 & 1.6 & 1.5 & 3.3 & 3 \\
\hline wrong & 6 & 11 & 1.7 & 1.6 & 3.4 & 8.8 \\
\hline hard-1 & 3 & 18 & 1.8 & 1.7 & 2.94 & 4.55 \\
\hline hard-2 & 13 & 6 & 1.7 & 1.7 & 4 & 4.5 \\
\hline
\end{tabular}

Accentuation of thematic centres is another phonostylistic feature which determines the stylisation of a monologue. In this dialogue, it is in the last dictema.

Jimmy: I knew more about love, betrayal and death, when I was ten years old than you will probably ever know all your life.

Lexemes constituting this thematic centre were contrasted with the background in the following ways: lexeme love was prominent only due to an increase in loudness (medium loudness); lexeme betrayal was not prominent; lexeme death was prominent due to pitch level and pitch range parameters. All three words were pronounced with Mid Fall. The results of this acoustic analysis are given in Table 2.

Table 2. Prosodic parameters of the thematic centre in a monologue (first thematic group)

\begin{tabular}{|c|c|c|c|c|}
\hline Lexeme & $\begin{array}{c}\text { Average pitch } \\
\text { level }\end{array}$ & Pitch range & $\begin{array}{c}\text { Average } \\
\text { loudness }\end{array}$ & Length (tempo) \\
\hline love & 1.01 & 0.43 & 1.22 & 1.10 \\
\hline betrayal & 1.02 & 1.14 & 0.94 & 0.86 \\
\hline death & 1.84 & 1.29 & 1.10 & 0.95 \\
\hline
\end{tabular}

The graphic representation of length (tempo), loudness and pitch parameters in this thematic centre is shown in Figure 1.

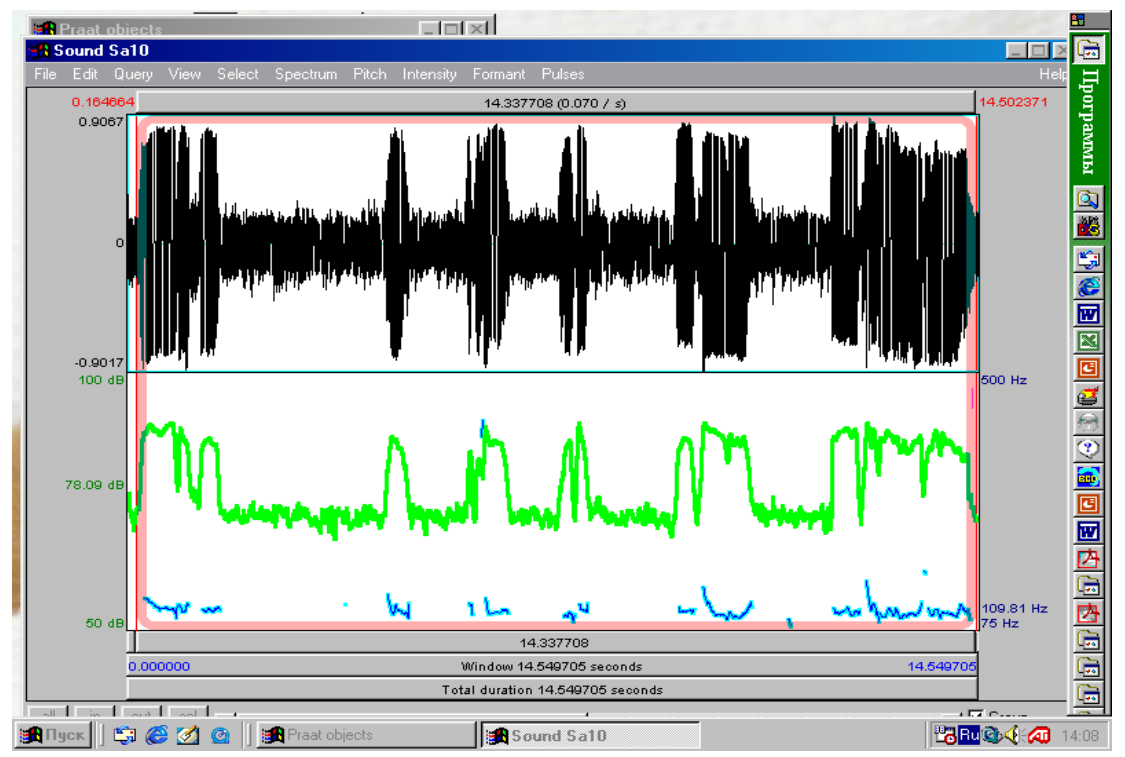

Figure 1. The intonogram of the thematic centre in a monologue (first thematic group)

This research also shows that in each of the monologues, apart from a thematic centre, there is an "expressively prominent centre". A thematic centre is 
linked to the main idea of the monologue while the expressively prominent centre includes prosodically prominent lexemes which bear modality and have a clear pragmatic function. In the above-mentioned Jimmy's monologue, auditory analysis detected the presence of three expressively prominent centres:

Jimmy: But, you see, I was the only one who cared.

... All he could feel was the despair and the bitterness, the sweet, sickly smell of a dying man.

... And I can never forget it.

The graphic representation of pitch parameters, loudness and length (tempo) in these prosodically prominent centres is shown in Figures 2-4.

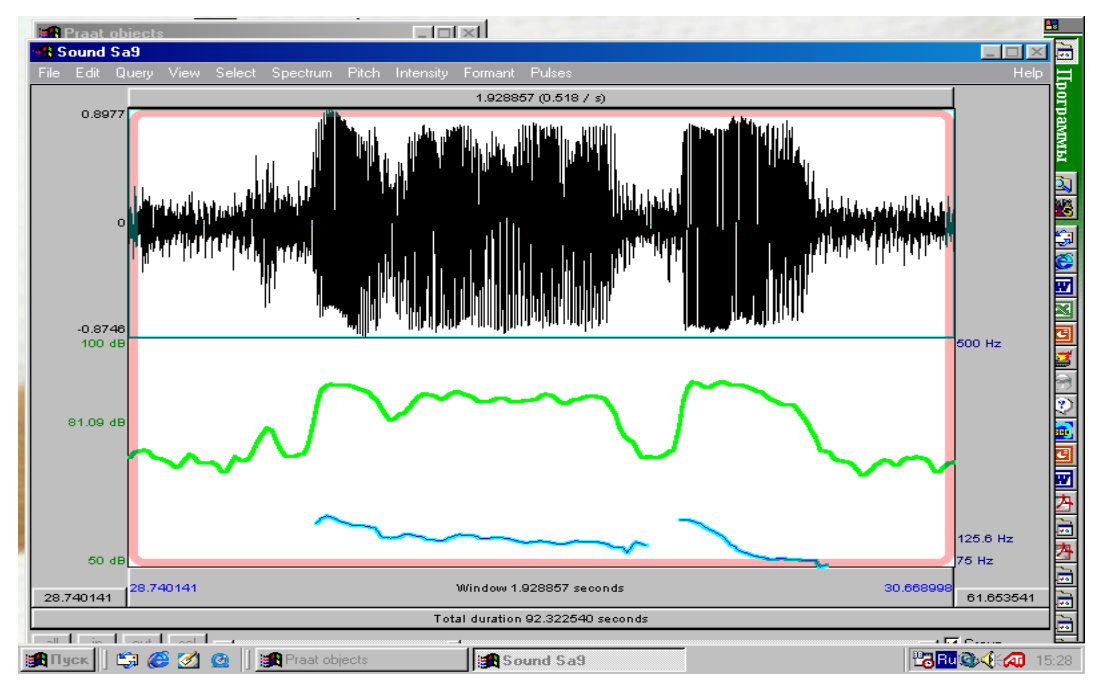

Figure 2. The intonogram of the first prosodically prominent centre in a monologue (first thematic group)

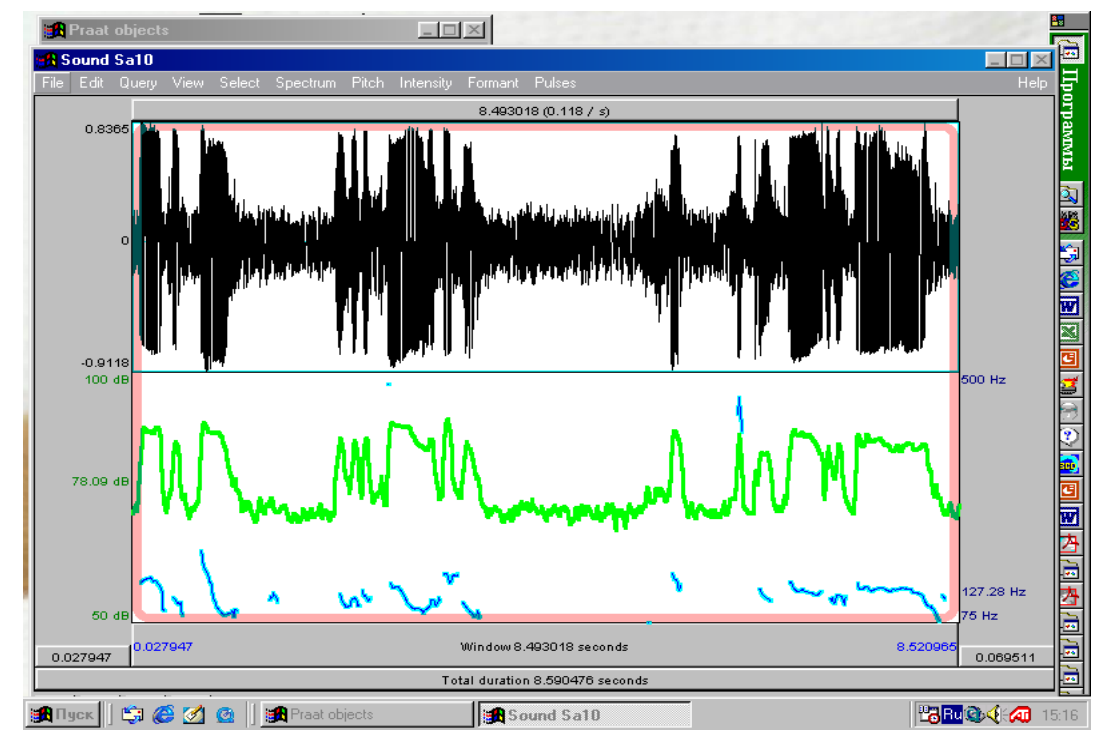

Figure 3. The intonogram of the second prosodically prominent centre in a monologue (first thematic group) 


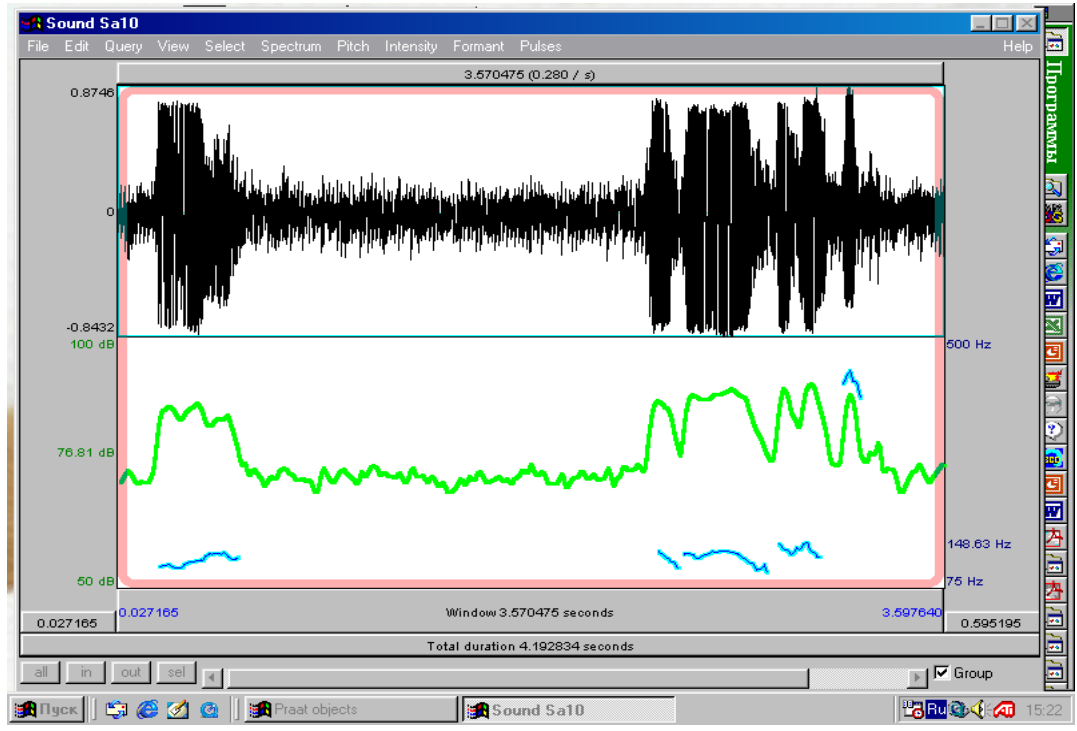

Figure 4. The intonogram of the third prosodically prominent centre in a monologue (first thematic group)

This research shows that composition scheme also has an essential role in stylisation of stage monologue. The kind of composition (1,2 or 3$)$ determines the position of the thematic centre in the monologue: in the first kind of composition scheme, the thematic centre is located either at the beginning or the end of the monologue; in the second kind of composition scheme, the thematic centre appears in the middle of the monologue; the third kind of composition scheme has the thematic centre placed at the beginning of the monologue, and repeats it at the end, forming a frame composition. A good illustration of this is the monologue from 'The Importance of Being Earnest' which exemplifies the first kind of composition scheme (the thematic centre is located at the end on the monologue):

Gwendolen: I wish you were fully forty-two,| and more than usually plain for your age.

Unlike it, the expressively prominent centre was in the second phrase:

Gwendolen: How secretive of him.

The acoustic analysis demonstrates that emotions and the expressively prominent centre slightly prevailed in this monologue, as demonstrated in the parameters of higher loudness, wider pitch range and slightly higher tempo (lexeme secretive). These results are depicted in Table 3.

Table 3. Correlation of prosodic parameters of the lexeme of the expressively prominent centre (second thematic group)

\begin{tabular}{|l|c|c|c|c|c|c|}
\hline \multirow{2}{*}{ Lexeme } & \multicolumn{2}{|c|}{$\begin{array}{c}\text { Pitch range } \\
\text { (in semitones) }\end{array}$} & \multicolumn{2}{|c|}{$\begin{array}{c}\text { Average loudness } \\
\text { (relative parameter) }\end{array}$} & \multicolumn{2}{|c|}{$\begin{array}{c}\text { Average length } \\
\text { (tempo) (in } \\
\text { syllable/sec) }\end{array}$} \\
\cline { 2 - 7 } & nucleus & background & nucleus & background & nucleus & background \\
\hline secretive & 3 & 2 & 1.8 & 1.5 & 3.7 & 3.6 \\
\hline
\end{tabular}


Unlike the first kind of composition scheme, the second had its expressively prominent centre in peak position, while in the frame category of composition, the thematic centre dominated the expressively prominent centre, which was marked prosodically.

A certain degree of stylisation is created by the theme in accordance with which a monologue develops. Thus, for the monologue belonging to the first thematic group (monologue with moral colouring), tone parameters, loudness and tempo were relevant in creating prominence. These were accompanied by Mid Fall and Stepping head and Mid-Level head:

Jimmy: I knew more about -|| love, | betrayal | and death, || when I was ten years old || than you will probably ever know | all your life.

love - increased loudness in combination with Mid Fall;

death - tone parameters in combination with Mid Fall;

ten - increased tempo combined with Fall-Rise;

probably - widening of pitch range combined with High Fall.

For the second thematic group (monologues characterising interpersonal relationships), the prominence of nuclear lexemes was also created by tone parameters and loudness:

Goldberg: That's why I've reached my position, McCann, | because I've always been as fit as a fiddle.

position, fiddle - increased pitch level and loudness in combination with High Fall. Accidental Rise on fit added to the required pragmatic effect (Table 4).

Table 4. Prosodic parameters of the thematic centre in a monologue (second thematic group)

\begin{tabular}{|c|c|c|c|c|}
\hline $\begin{array}{c}\text { Lexeme, } \\
\text { phraseme }\end{array}$ & $\begin{array}{c}\text { Average } \\
\text { pitch level }\end{array}$ & Pitch range & $\begin{array}{c}\text { Average } \\
\text { loudness }\end{array}$ & Length (tempo) \\
\hline position & 1.46 & 0.7 & 1.93 & 0.98 \\
\hline fit as a fiddle & 1.33 & 0.7 & 1.76 & 0.8 \\
\hline
\end{tabular}

In video films, the parameter of pitch range was also relevant - narrowing, combined with slower tempo and Low Fall on the nuclear lexeme. The abovementioned stylistic markers of stage monologue are summarised in Table 5.

Table 5. Stylistic markers of stage monologue (theatrical and film versions)

\begin{tabular}{|l|l|l|}
\hline Delimitation & phonodictemas - phrases - intonation groups \\
\hline $\begin{array}{l}\text { Style-marking } \\
\text { features }\end{array}$ & Loudness & $\begin{array}{l}\text { varies depending on the size of the audience scene } \\
\text { objectives }\end{array}$ \\
\cline { 2 - 3 } & $\begin{array}{l}\text { Pitch level and } \\
\text { pitch range }\end{array}$ & vary \\
\cline { 2 - 3 } & Tempo & $\begin{array}{l}\text { varies depending on the importance of } \\
\text { information and scene objectives }\end{array}$ \\
\hline
\end{tabular}




\begin{tabular}{|c|c|c|}
\hline & Pauses & $\begin{array}{l}\text { syntactical varying from short to very long, } \\
\text { emphatic - from long to very long }\end{array}$ \\
\hline & Rhythm & determined by the objective of the character \\
\hline \multirow{3}{*}{$\begin{array}{l}\text { Accentuation } \\
\text { of thematic } \\
\text { centres and } \\
\text { expressively } \\
\text { prominent } \\
\text { centres }\end{array}$} & Terminal tones & $\begin{array}{l}\text { wide usage of High, Mid and Low Fall in } \\
\text { thematic centres; the usage of Rise and Level } \\
\text { tones at the end of the intonation group }\end{array}$ \\
\hline & Pre-nuclear part & $\begin{array}{l}\text { variations in the usage of heads: descending, } \\
\text { ascending and Level heads; emphasis is achieved } \\
\text { through the usage of the following contours: } \\
\text { Mid Head + High Fall } \\
\text { Mid Head + Rise-Fall } \\
\text { Mid Head + Fall-Rise } \\
\text { High Head + Rise-Fall-Rise } \\
\text { Sliding Head + High Fall } \\
\text { Rising Head + High Fall }\end{array}$ \\
\hline & $\begin{array}{l}\text { Contrast } \\
\text { between marked } \\
\text { and unmarked } \\
\text { segments }\end{array}$ & $\begin{array}{l}\text { achieved through the usage of higher loudness, } \\
\text { High Fall and variations of tempo }\end{array}$ \\
\hline
\end{tabular}

\section{Practical value of textual and prosodic analyses for students}

Understanding stage text structure is crucial in looking into an oral monologue. In other words, anyone examining an oral text must comprehend how the information within it should be organised. This strategy can help learners to realise that a text should possess informational content based on the required topic; it must consist of one or more thematic units - dictemes - that are semantically complete; the analysed text ought to be characterised by continuum and a certain composition (introduction, main part and conclusion). An oral text generally demonstrates coherence (semantic integration) and cohesion (grammatical and lexical integration); it must prove to be complete from the point of view of the development of ideas.

Prosody is also vital in the analysis of oral text.

The importance of intonation is not so much that it is a part of a good accent, or of the right way of speaking, although it is true, of course, that a good pronunciation always includes correct intonation as well as correct articulation and rhythm (Halliday, 1970, p. 21).

Intonation can change meaning, with the exception of idioms and some set expressions, and very often in pronunciation of one and the same phrase, several intonation patterns can develop, each expressing a different meaning. The importance of intonation in stage speech was highlighted by Stanislavsky. In fact, stage speech intonation, depending on the theme, plot, epoch and individual style of the speaker, represents regular everyday speech, but is more exaggerated on the 
stage. Correct usage of intonation in an oral text greatly depends on a knowledge of intonation patterns and stylistic features, which have been researched in this work: rules of delimitation and pauses (short, long and very long), and accentuation of keywords - a skill which must be obtained through a teacher's explanation. Thematic centres and prosodically prominent centres are present in any monologue, and sometimes even coincide, but must reveal the required prosodic characteristics of pitch (melody), intensity (loudness) and the rate of utterance (tempo). Compositional scheme and the theme of the monologue can also be included in style-forming factors characterising the artistic intonational style, because tone parameters, loudness and tempo vary depending on the thematic group and the theme.

The knowledge of stage monologue's textual and prosodic features, and the comprehension of certain intonation patterns can help learners to obtain the necessary phonetic competence; they can use this understanding and skill in reading theatrical monologues when acting in amateur stage performances, differentiating these features from other intonational styles.

These results may seem difficult for school learners, but can be relevant for university students training to be teachers who study each of the language subjects (Phonetics, Grammar and Lexis) as separate units. They also offer a serious basis for researchers into text and prosody. The skills of producing correct stylistically and semantically oral monologues in English can be developed with the help of engaged English teachers who work on the content of the text (Aini, 2020), and teachers who, according to research by Hanif (2021), correct mistakes in pronunciation.

\section{CONCLUSION}

Stage monologue in this research is referred to as an oral text which belongs to artistic intonational style. Results of the study prove that it can be analysed from lexico-grammatical and prosodic points of view. It has certain lexico-grammatical features - specific as compared to any other monologue - and is a coherent and complete text which is well structured and possesses a definite informational content. It also has certain textual features which demonstrate its expressiveness, normativeness and conversational character. Prosodic analysis of stage monologue allows deductions about, firstly, its specific prosoding colouring, which is created by particular prosodic markers, including pitch level and pitch range variations, loudness and tempo differences that add to its stylistic specificity, and, secondly, its style-forming factors.

This research is limited to the analysis of stage monologue carried out on theatrical and film presentations. Further exploration could involve comparing and contrasting it to, for example, a spontaneous monologue within the same thematic schemes, developing similarities and differences on both lexico-grammatical and prosodic levels. These results can also be of practical value, since spontaneous speech refers to conversational style, which is one of the intonational styles taught in any university course. 


\section{REFERENCES}

Aini, S. (2020). An Arabic text as content in an Indonesian EFL setting. Indonesian TESOL Journal, 2(2), 128-142. DOI: 10.24256/itj.v2i2.1518.

Aristotle. (1927). Poetics. Leningrad: Academia. https://kniganika.ru/antikvarnyeknigi/knigi-izdatelstva-academia/aristotel-poetika

Blokh, M. (2000). Dictema in the hierarchical structure of a language//Voprosy yazykoznaniya, https://via.ruslang.ru/ru/archive/2000-4/56-67

Blokhina, L.P., \& Potapova, R. K. (1977). Methodological recommendations: Methods of analysis of prosodic characteristics of speech. Moscow: MSLU. https://istina.msu.ru/publications/book/4904380

Cruttenden, A. (1997). Intonation. Cambridge: Cambridge University Press. https://www.google.com/search?q=Cruttenden\%3F+1977\%2C+Intonation\&

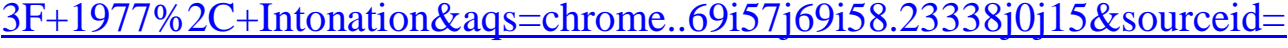
chrome\&ie $=\mathrm{UTF}-8$

Dubovsky, Yu. A. (1978). Analysis of intonation and its components. Minsk: Vysheyshaya shkola. (Cited in https://www.dslib.net/germanskiejazyki/prosodija-kak-factor-stileobrazovanija-jeksperimentalnofoneticheskoe-issledovanie.html)

Galperin, I. R. (2006). Text as an object of linguistic research. Moscow: KomKniga. https://studylib.ru/doc/4271828/i.-r.-gal._perin.-tekst-kak-obektlingvisticheskogo-issled...

Halliday,M. (1970). Course of Spoken English Intonation. London: Oxford University Press. https://www.worldcat.org/title/course-in-spoken-englishintonation-by-mak-halliday/oclc/301705781

Hanif, H. (2021). Spoken Error Correction Practices and Beliefs of EFL University Teachers in Saudi Arabia. Indonesian TESOL Journal, 3(1), 68-75). DOI: 10.24256/itj.v3i1.1739.

Krylova, L.V. (1979). Linguistic peculiarities of monologue in drama. Candidate of Sciences dissertation. Moscow: MGPIIYA. Cited in: https://books.google.ru/books?id=jQeHCwAAQBAJ\&pg=PT42\&lpg=PT42 \&dq $=\%$ D0\%9A $\%$ D $1 \% 80 \% \mathrm{D} 1 \% 8 \mathrm{~B} \% \mathrm{D} 0 \% \mathrm{BB} \% \mathrm{D} 0 \% \mathrm{BE} \% \mathrm{D} 0 \% \mathrm{~B} 2 \% \mathrm{D} 0 \% \mathrm{~B} 0$ , $\%$ D0\%9B+\%D0\%92,+\%D0\%9B\%D0\%B8\%D0\%BD\%D0\%B3\%D0\%B2 \%D0\%B8\%D1\%81\%D1\%82\%D0\%B8\%D1\%87\%D0\%B5\%D1\%81\%D0\% BA\%D0\%B8\%D0\%B5+\%D0\%BE\%D1\%81\%D0\%BE\%D0\%B1\%D0\%B5 $\% \mathrm{D} 0 \% \mathrm{BD} \% \mathrm{D} 0 \% \mathrm{BD} \% \mathrm{D} 0 \% \mathrm{BE} \% \mathrm{D} 1 \% 81 \% \mathrm{D} 1 \% 82 \% \mathrm{D} 0 \% \mathrm{~B} 8+\% \mathrm{D} 0 \% \mathrm{BC} \% \mathrm{D}$ 0\%BE\%D0\%BD\%D0\%BE\%D0\%BB\%D0\%BE\%D0\%B3\%D0\%B8\%D1\%8 7\%D0\%B5\%D1\%81\%D0\%BA\%D0\%BE\%D0\%B3\%D0\%BE+\%D0\%B2\% D1\%8B\%D1\%81\%D0\%BA\%D0\%B0\%D0\%B7\%D1\%8B\%D0\%B2\%D0\% B0\%D0\%BD\%D0\%B8\%D1\%8F,+1979\&source=bl\&ots=qfi\#v=onepage\&q $=\% \mathrm{D} 0 \% 9 \mathrm{~A} \% \mathrm{D} 1 \% 80 \% \mathrm{D} 1 \% 8 \mathrm{~B} \% \mathrm{D} 0 \% \mathrm{BB} \% \mathrm{D} 0 \% \mathrm{BE} \% \mathrm{D} 0 \% \mathrm{~B} 2 \% \mathrm{D} 0 \% \mathrm{~B} 0 \% 2$ C\%20\%D0\%9B\%20\%D0\%92\%2C\%20\%D0\%9B\%D0\%B8\%D0\%BD\%D0 \%B3\%D0\%B2\%D0\%B8\%D1\%81\%D1\%82\%D0\%B8\%D1\%87\%D0\%B5\% D1\%81\%D0\%BA\%D0\%B8\%D0\%B5\%20\%D0\%BE\%D1\%81\%D0\%BE\%D 
0\%B1\%D0\%B5\%D0\%BD\%D0\%BD\%D0\%BE\%D1\%81\%D1\%82\%D0\%B 8\%20\%D0\%BC\%D0\%BE\%D0\%BD\%D0\%BE\%D0\%BB\%D0\%BE\%D0\% B3\%D0\%B8\%D1\%87\%D0\%B5\%D1\%81\%D0\%BA\%D0\%BE\%D0\%B3\% D0\%BE\%20\%D0\%B2\%D1\%8B\%D1\%81\%D0\%BA\%D0\%B0\%D0\%B7\% D1\%8B\%D0\%B2\%D0\%B0\%D0\%BD\%D0\%B8\%D1\%8F\%2C\%201979\&f $=$ false

Petrova, A.N. (1981). Stage speech. Moscow: Iskusstvo. https://www.livelib.ru/book/1000547192-stsenicheskaya-rech-an-petrova

Sanger, K. (2001). The language of drama. London and New York: Routledge. https://openlibrary.org/works/OL2677279W/The_language_of_drama

Richards, J. C. (2015). Key Issues in Language Teaching. Cambridge: Cambridge University Press. https://www.professorjackrichards.com/wpcontent/uploads/Key-Issues-in-Language-Teaching-Reviewed-by-Le-VanCanh.pdf

Sokolova, M.A., Gintovt, K.P., Tikhonova, I.S., \& Tikhonova R.M. (1991). Theoretical Phonetics of the English Language. Moscow: "Higher School". https://www.alib.ru/au-sokolova/nmteoreticheskaya_fonetika_anglijskogo_yazyka/

Sokolova, M., Gintovt, K., Kanter, L., Krylova, N., Tikhonova, I., \& Shabadash, G. (1997).

Practical Phonetics of the English Language. Moscow: VLADOS. https://www.studmed.ru/sokolova-m-a-prakticheskaya-fonetika-angliyskogoyazyka_8399c48ca41.html

Stanislavsky, K.S. (1954-1961). A collection of works in 8 volumes. Vol. 3. Moscow: Iskusstvo. https://www.studmed.ru/stanislavskiy-sk-sobraniesochineniy-v-vosmi-tomah

www.oplib.ru/...521185 the_phonetic_style_forming_means. Retrieved 14 November 2017.

Wells, J.C. (2007). English Intonation. An Introduction. Cambridge: Cambridge University Press. https://www.worldcat.org/title/english-intonation-anintroduction/oclc/254241668

Yakubinsky, L.P. (1923). On dialoguing. In L.V. Scherba (Ed.), A collection of articles. Ch.2. (pp. 96-195). Petrograd: Phonetic institute. https://crecleco.seriot.ch/textes/Jakubinskij23b.html 